\title{
Analysis of Amorphous Metal Core Distribution Transformer
}

\author{
Pandav Sharoniben . $\mathbf{J}^{1}$, Parmar Jaydipsinh. $\mathbf{K}^{2}$ \\ ${ }^{1}$ M.E Student, Electrical Engineering Department, Shantilal Shah Engineering College, Bhavnagar, Gujarat, India \\ ${ }^{2}$ Assistant Professor, Electrical Engineering Department, Shantilal Shah Engineering College, Bhavnagar, Gujarat, India
}

\begin{abstract}
It is current issue to require the balance the electrical power generation and electrical energy consumption. Due to this many energy conservation techniques and renewable energy sources used at side of consumer and utility side. Amorphous metal used for the made of core of transformer. Because of unique properties of Amorphous metal reduce the eddy current losses and hysteresis losses. So it can conserve the electrical energy by reduce the transformer losses. Amorphous metal core distribution transformer reduce the 70 to 80 percentages losses as compare to the conventional transformer.
\end{abstract}

Keywords: AMDT Amorphous Metal Distribution transformer, CRGO Cold Rolled Grain Oriented, NLL No Load Losses, TOC Total Owning Cost, $\mathrm{CO}_{\mathrm{x}}$ and $\mathrm{SO}_{\mathrm{x}}$.

\section{Introduction}

Distribution transformers are energized for twenty four hours with wide and different variation in load; therefore distribution transformers are required to have low no-load losses. So I focuses in this paper minimize the NLL no load losses by using amorphous metal core distribution transformer(AMDT) and calculated the savings no load losses, cost of load losses per year in Rs. saved generated capacity required to feed no load losses. Amorphous metal core have different magnetic Properties. Due to lack of such features amorphous metal magnetize and demagnetize easily than crystalline metals. The atomic non-crystalline structure and high solute content of amorphous metal reduce the mean free path of electrons, resulting in electrical resistivity two to three times of more than crystalline alloys. Amorphous metal alloys have high resistivity. High electrical resistance in the magnetic component reduces eddy current produced by domain-wall motion. So the eddy current component of magnetic losses is minimized in amorphous metals [1].Several economical and environmental benefits using amorphous core transformer. Applications where using AMDT is most beneficial, such as in renewable energy generation [2]. Many Factors Affecting the Design of transformer Comparison with Conventional CRGO core Transformers. Stacking factor (Ks) is defined by the ratio between the cross-sectional area of ferromagnetic material and total cross-sectional area of the core. Which is for the CRGO steel it is 0.9 or higher and for amorphous alloy it is in between 0.8 and 0.9.In case of amorphous core transformers, the reluctance offered by magnetic path is much less about $1 / 4$ of reluctance offered in conventional CRGO core transformer which reduces the magnetic asymmetry, resulting reduction in zero sequence current [3].With using 4-stepped amorphous core, we can increase efficiency of transformer and uniform redial force [4]. Improving Amorphous transformer designs and better manufacturing techniques for producing transformer cores will result in improved transformer efficiency and lower total owning costs for amorphous transformers[5].

\section{Different Methods for Reduce Losses}

Although there are different methods used for the reducing No load losses and load losses of the transformer .. The objective of this paper is to find ways to reduce the distribution transformer No-load losses and evaluate a single method of loss reduction for use in amorphous metal distribution transformer in distribution network. By using electric shield, decreasing flux path, we can reduce the 21 to 25 percentage of No load losses. By Use of influence of transformer core design (Hexa - transformer), we can reduce 50 percentage of No load losses, but using Amorphous metal core transformer we can reduce the 60 to 70 percentage Noload losses.

\section{Properties of Amorphous metal core}

There are many factors affected to design of transformer. Stacking factor, which is ratio between the cross-sectional area of ferromagnetic material and total cross-sectional area of the core,is the 0.9 or more than 0.9 for the CRGO core transformer and 0.8 to 0.9 for the amorphous core transformer, Another most important factors, Loss factors affect the transformer. For the specific core loss for CRGO core transformer 0.9 to 1.5 watt $/ \mathrm{kg}$ and for the Amorphous core 0.1 to 0.2 watt $/ \mathrm{kg}$ at 50 Hertz and 1.4 Tesla.Specific Resistance for the CRGO core is $45 \mathrm{Ohm}$ and for the Amorphous core $130 \mathrm{Ohm}$. So specific resistance low for the amorphous core .It can be reduce the eddy current losses of Amorphous transformer. Different properties for amorphous transformer are below, with the cooperation of CRGO core. 


\section{International Journal of Science and Research (IJSR) \\ ISSN (Online): 2319-7064}

Index Copernicus Value (2013): 6.14 | Impact Factor (2015): 6.391

Table 1: Properties of Amorphous metal and Silicon steel core

\begin{tabular}{|c|c|c|c|c|}
\hline S. No & Properties & $\begin{array}{c}\text { Amorphous } \\
\text { Metal Core }\end{array}$ & $\begin{array}{c}\text { Silicon Steel } \\
\text { Core }\end{array}$ & Unit \\
\hline 1 & Flux density & 7.15 & 7.65 & $\mathrm{~g} / \mathrm{cm}$ \\
\hline 2 & Specific Resistance & 130 & 45 & Ohm \\
\hline 3 & Saturation flux density & 1.56 & 2.03 & Tesla \\
\hline 4 & Specific core loss & 0.10 to 0.20 & 0.90 to 1.5 & watt $/ \mathrm{kg}$ \\
\hline 5 & Thickness & 0.025 & 0.27 & $\mathrm{Mm}$ \\
\hline 6 & Space factor & 0.8 to 0.9 & $\begin{array}{c}0.9 \text { or more } \\
\text { than } 0.9\end{array}$ & \\
\hline 7 & Brittleness & Higher & Lower & \\
\hline 8 & Available in the form of & $\begin{array}{c}\text { Ribbon/ } \\
\text { Foil }\end{array}$ & $\begin{array}{c}\text { Sheet/ } \\
\text { Roll }\end{array}$ & \\
\hline
\end{tabular}

\section{Transformer Design}

Table 2: Equations of design of transformer.

\begin{tabular}{|l|l|}
\hline \multicolumn{2}{|l|}{ EQUATIONS CORE DESIGN } \\
\hline 1. & Iron area $\mathrm{Ai}=\mathrm{Et} / 4.44 \mathrm{Bm} \mathrm{f}$ \\
\hline 2. & $\begin{array}{l}\text { Diameter of circle } \mathrm{d}=\sqrt{ }\left(\mathrm{Ai}^{*} 4 / \text { \{ core space factor*stacking }\right. \\
\text { factor* } \pi \text { \} }\end{array}$ \\
\hline 3. & Net $\mathrm{Ai}=\left(\right.$ core sapce factor* stacking factor $\left.* \pi * \mathrm{~d}^{2}\right) / 4$ \\
\hline 4. & laminations $\mathrm{a}=0.92 * \mathrm{~d}$ \\
\hline WINDOW DESIGN \\
\hline 5. & Window area $\mathrm{Aw}=\mathrm{Q} / 3.33 \mathrm{Ai} \mathrm{Kw} \delta \mathrm{Bm} \mathrm{f} 10^{3}$ \\
\hline 6. & Window width $\mathrm{Ww}$ \\
\hline 7. & window height $\mathrm{Hw}$ \\
\hline
\end{tabular}

\section{YOKE DESIGN}

8. $\quad$ Area of yoke=1.2*Area of iron

$9 . \quad$ Depth of Yoke Dy $=\mathrm{a}$

10. Height of yoke Hy = Gross area of Yoke/Depth of Yoke

11. Net area of the yoke= Dy * Hy

12. Width of frame $=2 *$ Distance between adjacent core centre $+a$

13. Height of frame=Height of window $+(2 * a)$

\section{WINDING DESIGN L.V WINDING}

14. $\quad$ No. of turns T 1=V/Phase / V/turns Et

15. Inside diameter of $\mathrm{L} . \mathrm{V}$ D1 $=\mathrm{d}+2$ clearance

16. $\quad$ Area of L.V conductor a2= L.V current I/current density $\delta$

17. Outside diameter of L.V D2=D1+2 Width of winding

\section{H.V WINDING}

$18 . \quad$ No. of turns T 2=H.V KV*L.V turns/L.V Voltage per phase

19. Area of H.V conductor a1 $=\mathrm{H} . \mathrm{V}$ current I/current density $\delta$

20. Inside diameter of H.V D3=D2+2 clearance

21. Outside diameter of H.V D4=D1+2 Width of winding

22. Mean diameter length $\mathrm{L} . \mathrm{V}=3.14(\mathrm{D} 1+\mathrm{D} 2) / 2$

23. Mean diameter length $\mathrm{H} . \mathrm{V}=3.14(\mathrm{D} 3+\mathrm{D} 4) / 2$

CORE LOSS

24 Weight of iron $=\left\{\mathrm{Ai}^{*}\right.$ (over all width of yoke and

24. ${\text { core } * 2)\}+\left\{\text { Ay* }^{*}(\text { Height of window*3) }\} * 7.85 * 1000 /\left(10^{6} * 10^{3}\right)\right.}$

25 . Core loss=Specific core loss for CRGO*Weight of frame

\section{COPPER LOSS}

26. $\quad$ Total weight = Weight of L.V winding + Weight of H.V

26. winding

27. Resistance of L.V winding $=(0.034 *$ Mean length *No. of turns)/area*1000

28. Resistance of H.V. winding $=(0.034 *$ Mean length $*$ No. of turns)/area*1000

29. Equivalent resistance referred to H.V/phase=Resistance of L.V.winding+Resistance of H.V. winding $+\mathrm{KV}$ ratio Copper loss $=3 * \mathrm{I}^{2} *$ Equivalent resistance Efficiency $=\left[\left(\mathrm{KVA}^{*} 1000\right) /\left\{\mathrm{KVA}^{*} 1000\right)+(\right.$ Iron loss + Copper loss) $\}] * 100$

\section{63 KVA Transformer design}

In this paper, design the circular core of CRGO transformer and rectangular core of amorphous core of transformer. Amorphous core mainly design in rectangular core because of its brittleness properties.

Table 3: Calculations of design of 63KVA transformer with amorphous core and CRGO core

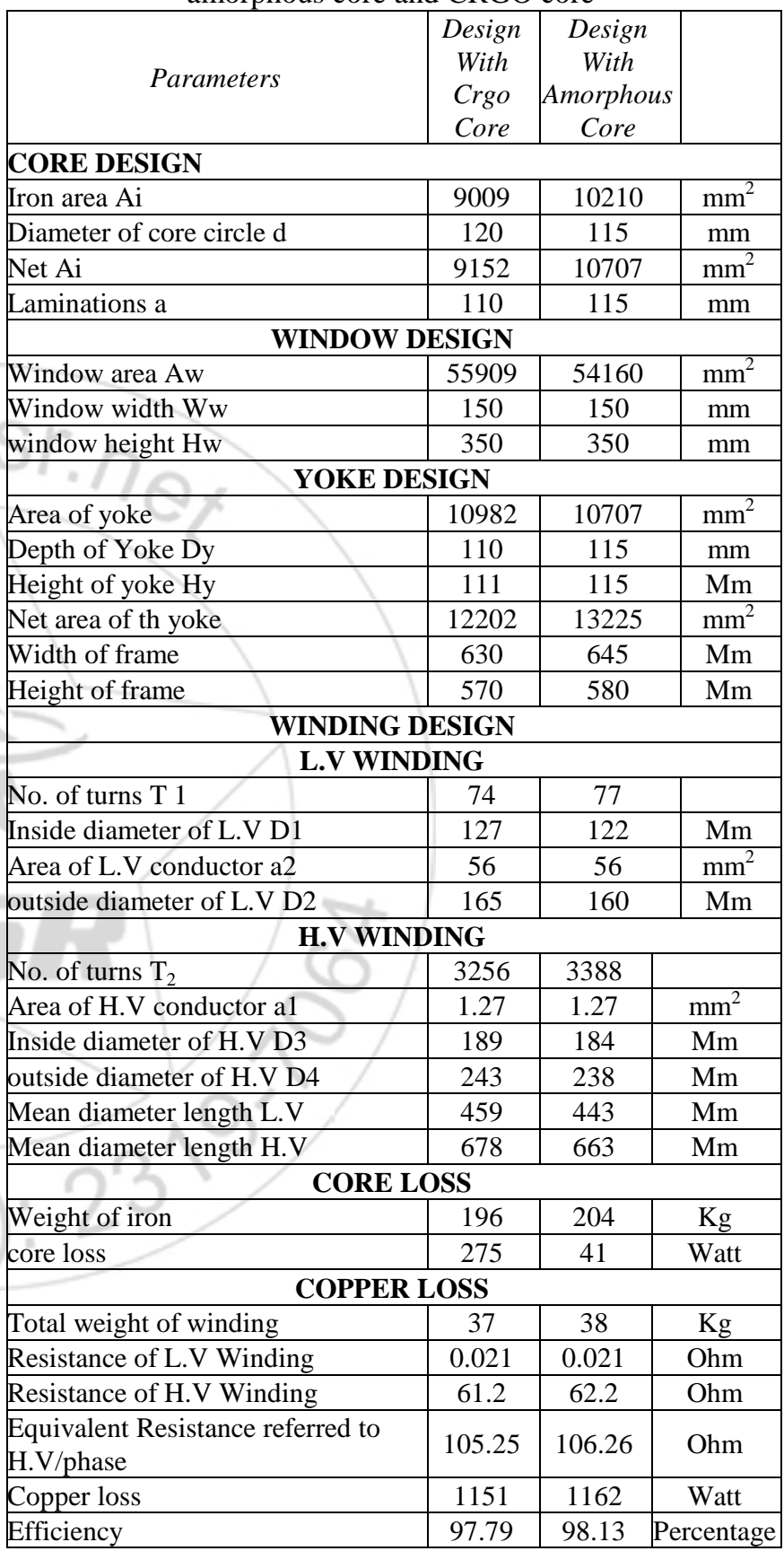

So by this design of transformer we can see that the Amorphous core distribution transformer has high efficiency is more than CRGO core transformer, Due to the No- load losses of the amorphous core are less. 


\section{International Journal of Science and Research (IJSR) \\ ISSN (Online): 2319-7064 \\ Index Copernicus Value (2013): 6.14 | Impact Factor (2015): 6.391}

Table 3: Investment saved with use of Amorphous core transformer.

\begin{tabular}{|c|c|c|}
\hline NOLOAD LOSSES OF CRGO(in watt) & 275 & Watt \\
\hline NOLOAD LOSSES OF AMDT(in watt) & 41 & Watt \\
\hline difference in losses=275-41 & 234 & Watt \\
\hline If no. of transformer & 150000 & \\
\hline save energy in watt=234*150000 & 35100000 & Watt \\
\hline save energy in Kw=35100000 / 1000 & 35100 & Kw \\
\hline $\begin{array}{c}\text { GENERATED CAPACITY SAVED IN } \\
\text { MW=MW*System losses up to distribution } \\
\text { transformer/Plant load factor (for generation) } \\
=(35.1 * 1.15) / 0.60\end{array}$ & 35.1 & Mw \\
\hline $\begin{array}{c}\text { Saving energy cost=saving energy in } \\
\text { Kw*8760*3*1=Mw * total hours in }\end{array}$ & Mw \\
$\begin{array}{c}\text { year*Cost of energy at the transformer } \\
\text { terminals (in Rs.) }\end{array}$ & 9200000 & Rs. \\
\hline $\begin{array}{c}\text { Saving energy cost in Rs/Annum } \\
\text { Investment saved in installing generation } \\
\text { capacity(in Rs.)=Saving energy cost in } \\
\text { Rs*Cost of Installation of } 1 \text { MW Generation } \\
\text { (Thermal) =92 CroreRs.*5 Crore Rs. }\end{array}$ & 461 & crore Rs \\
\hline
\end{tabular}

So by using Amorphous core it can be saved generated capacity in $\mathrm{Mw}$ and Investment saved in installing generation capacity (in Rs.)

Table 3: Basic assumption used for above calculations Basic assumptions used:

(i)Number of distribution transformers added in the Indian Power System every year $=1,50,000$ (For average capacity $63 \mathrm{kva}$ )

(ii) Cost of Installation of 1 MW Generation (Thermal) = Rs.5 Crore

(iii ) Cost of energy at the transformer terminals $=$ Rs. $3 / \mathrm{kwh}$

(iv) Plant load factor (for generation) $=60 \%$

(v) System losses up to distribution transformer $=15 \%$

\section{Total Owning Cost}

TOC = Initial Cost of Transformer + Cost of No-load Losses

+ Cost of Load Losses. OR

TOC $=$ Initial Cost of Transformer $+A^{*}($ No Load losses $)+$ B* (Load losses)

Capitalization of Losses of the Distribution transformer is used for equipment in the power distribution network. Due to poor performance of the transformers load and no load losses occur throughout the life of the system causing revenue degeneration year after year. To illustrate the effect of these losses, the capitalized costs are determining the Total owning cost for distribution transformer in Indian Power System.

According to [6] calculation of TOC is very easy way and compare the TOC of the CRGO core and Amorphous core transformer .To calculate the capitalized cost of no load losses, the guidelines suggested by an expert committee consisting of representatives ;

1. State Electricity Boards (SEBs),

2. Central Board of Irrigation and Power (CBIP),

3. IEEMA

4. Rural Electrification Corporation (REC)
Are used in this paper.

$$
A=\mathrm{H} * \mathrm{E} *\left[\frac{(1+\mathrm{r})^{\mathrm{n}}-1}{\mathrm{r} *(1+\mathrm{r})^{\mathrm{n}}}\right]
$$

Where,

A = Capitalized cost of No-load losses in Rs. $/ \mathrm{kW}$

$\mathrm{H}=$ No. of service hours per year of the distribution transformer

$r=$ Rate of interest

$\mathrm{n}=$ Life of transformer in a year

$\mathrm{E}=$ Energy Cost, i.e. the cost of electrical energy at the bus to which transformer is to be connected (Rs/kWh).

$$
\mathrm{B}=\mathrm{A}^{*} \text { Loss factor }
$$

Where,

$\mathrm{B}=$ Capitalized cost of No-load losses in Rs./kW

A and B the capitalized cost of the transformer (TOC) may be given by

$$
\mathrm{TOC}=\text { Initial Cost }+(\mathrm{A} * \mathrm{Wi})+(\mathrm{B} * \mathrm{Wc})
$$

Where,

IC = Initial cost of transformer (Rs)

$\mathrm{Wi}=$ No load losses of the transformer

$\mathrm{WC}_{\mathrm{C}}=$ Load losses of the transformer

According to Rural Electrification Corporation REC the values described for various parameters.are ,

1. No. of service hours: $H=350 * 24=8400$ hrs: (Assum that transformer does not in service for 15 days in a year due to repair and maintenance)

2. Life of transformer: $n=25$ years

3. Rate of interest $=12 \%$

4. Loss load factor (LS): Given in terms of the load factor (LF)

$$
\mathrm{LS}=0.2 \mathrm{LF}_{1}+0.8 \mathrm{LF}_{2}=0.132
$$

$\mathrm{E}=$ Assum energy charges as Rs 2.70 per unit at $63 \mathrm{KV}$

So ,

The Initial cost of the CRGO core transformer $=$ Rs.37140

Initial core of Amorphous core transformer =Rs.62840.

TOC of the CRGO core transformer = Rs. 1,13,083

TOC of the Amorphous core transformer $=$ Rs. 97,417

So The Initial cost of the Amorphous core transformer has more than to the CRGO transformer but it is recover in few months, which can be find the break -even point . Total owning cost with the cost of no-load losses and load losses of the amorphous core transformer the less than to the CRGO core transformer. 


\section{International Journal of Science and Research (IJSR) \\ ISSN (Online): 2319-7064}

Index Copernicus Value (2013): 6.14 | Impact Factor (2015): 6.391

\section{Conclusion}

So ,by using amorphous metal core distribution transformer we can reduce the No-load losses It is resulted that we can save the generation capacity and reduce the generation of CO ${ }_{x}$ and $\mathrm{SO}_{\mathrm{x}}$. So it can be save the generation capacity, which are ours economical and environmental benefits .

\section{References}

[1] Md. Aminul Islam Member, IEEE, IEEE Bangladesh Section, Dhaka,Bangladesh, " Prospective Analysis of Energy Efficient Amorphous Metal Distribution Transformer (AMDT)",978-1-4577-0547-2/12, 2012, IEEE.

[2] Martin Carlen, Member, IEEE, David Xu, Member, IEEE, Johannes Clausen,Tommy Nunn,V.R.Ramanan,Member,IEEE,Douglas $\quad$ M Geston,Member IEEE, "Ultra High Efficiency Distribution Transformers" ,ISBN:978-1-4244-6547-7 ,2010,IEEE.

[3] Man Mohan ,Electrical Engineering Department, Faculty of Engineering, D.E.I., Dayalbagh, Agra-282005,India "An Overview on Amorphous Core Transformers”,ISBN: (ISSN: 2141-7016) , Published: Scholarlink Research Institute Journals, 2012 .

[4] Man Mohan ,Electrical Engineering Department, Faculty of EngineeringD.E.I., Dayalbagh, Agra-282005, India. “ Distribution Transformer with Multi-Stepped Amorphous-Core" ,Journal of Emerging Trends in Engineering and Applied Sciences (JETEAS) 3 (2): 265269 C Scholarlink Research Institute Journals, 2012 (ISSN: 2141-7016).

[5] Herry W. NG, Senior member, IEEE, Rysuke Hasegawa, Fellow, IEEE, Albert C. LEE, Life senior member, IEEE, Larry A. Lowdermilk, member, IEEE , "Amorphous Alloy Core Distribution Transformers", 0018-9219/91, 1991 IEEE,Proceeding of the IEEE, VOL. 19, NO. 11, NOVEMBER 1991.

[6] Gayatri Agnihotri, Savita Nema, R. K. "Nema, Department of Electrical Engineering Maulana Azad National Institute of Technology, Bhopal (M.P.) INDIA, "Amorphous Core Distribution Transformers: Challenges, Opportunity and Loss Capitalization for Power Applications in India", Recent Researches in Circuits, Systems, Mechanics and Transportation Systems,ISBN: 978-1-61804-062-6 ,Page no-172.

[7] Simon Kiptum Kimitei. "Energy saving in electricity distribution networks through the use of Amorphous metal distribution transformer".A case study of The Kenya Power \& Lighting Company Distribution Networ,I (F56/63937/2010) , Year 2010,A Research Project Report.

[8] Poonam Lutchman , "evaluation of efficient transformer core design", A Dissertation reportof the degree of Master of Science in Engineering.

[9] Mr. Tarak Shah , "Case Study on Gujarat Electricity Board - A Benchmark in the progress of SEB reforms", National training program for C \& D employees operation \& maintenance of distribution transformer,prevention of failure and repairs (Variant: DIST TFs) ,REC,Ministry of power.

[10] A.K SAWHNEY, Course in electrical machine design. 2004.

[11] M.G.SAY, The performance and design of alternating current machines, Third edition.

[12] M.V.Deshpande, Design and Testing of Electrical Machines,2013.

\section{Author Profile}

Pandav Sharoniben . J received the B.E. degrees in Electrical Engineering from Government engineering college, Modasa, Gujarat in 2002. 